\title{
Testing the activitystat hypothesis: authors' response
}

\author{
Anna Goodman ${ }^{1}$, Roger L. Mackett ${ }^{2} \&$ James Paskins ${ }^{2}$ \\ ${ }^{1}$ Department of Epidemiology and Population Health, London School of Hygiene and Tropical \\ Medicine, London UK; \\ ${ }^{2}$ Centre for Transport Studies, University College London, London UK
}

Corresponding author: Anna Goodman, London School of Hygiene \& Tropical Medicine, Keppel Street, London, WC1E 7HT, UK (anna.goodman@1shtm.ac.uk).

Note: this is a personal version, created by Anna Goodman, of the text of the accepted letter. It does not incorporate any minor modifications made at the proof stage. The complete citation for the final letter is:

- Goodman, A; Mackett, RL; Paskins, J; (2012) Testing the activitystat hypothesis: Authors' response. Prev Med. 54 (2) pp. $178-179$

- DOI: 10.1016/j.ypmed.2011.12.010

Copyright (C) and Moral Rights for this paper are retained by the individual authors and/or other copyright owners 


\section{LETTER}

The activity hypothesis states that children compensate for highly-active periods by being less active at other times because of the homeostatic regulation of total energy expenditure by an 'activitystat' in children's central nervous system. We agree with Wilkin and Metcalf (2012) that this hypothesis is important, should be tested rigorously, and is best evaluated 'following perturbation': as our paper states "confirmation in intervention studies is required". At present, however, we feel our research contributes to a literature in which definitive experimental evidence is lacking. For example, Wilkin and Metcalf cite two primary research papers in support of the activitystat hypothesis. The first observational study sampled 206 children from an out-of-town private preparatory school, a village state primary school and an inner-city primary school (Fremeaux et al., 2011). Children in the private school were more physically active within school but no different from the other two schools overall. This is certainly consistent with the activitystat hypothesis, but interpretation is arguably complicated by other differences between the schools (e.g. in location, socio-economic privilege, day-school vs. partially boarding school). The second intervention study evaluates a school-based physical activity (PA) programme (Kriemler et al., 2010). This reported a significant positive difference between intervention and control groups in mean school-time PA counts/minute $(0.92,95 \% \mathrm{CI} 0.35,1.50)$, a non-significant negative trend in out-of-school PA $(-0.14,95 \% \mathrm{CI}-0.51,0.22)$ and a non-significant positive trend overall $(0.21$, $95 \% \mathrm{CI}-0.21,0.63)$. While consistent with the activitystat hypothesis, this is equally consistent with the interpretation that the study was adequately powered to detect changes in school-time PA but not in total PA (reflecting the general statistical phenomenon that more power is needed for broad outcomes going beyond the specific intervention target). This second interpretation is perhaps supported by the intervention group's decreased body fat and increased aerobic fitness, suggesting a genuine increase in PA.

Regarding our methods, we followed conventional practice in defining 'moderate-to-vigorous physical activity' (MVPA) as all activity above the moderate intensity cut-point. Wilkin and Metcalf's comment that MVPA "may not have involved any vigorous activity, and therefore invite no compensation" seems to imply that compensation is only expected with respect to vigorous PA. This had not been our understanding, and seems inconsistent with the use of MVPA in activitystat research from Wilkin's group, again defining MVPA as everything above the moderate-intensity cut-point (e.g. Fremeaux et al., 2011). As Wilkin and Metcalf note, although our paper presents this MVPA measure, we report obtaining the same results for total volume of physical activity defined as mean counts/minute. We used 'mean counts' rather than the 'sum of all counts' as we believed that increased sleeping time was not hypothesised to be a major mechanism underlying activity compensation. As such, and contrary to Wilkin and Metcalf, we felt the sum of all counts would be more confounded by differences in waking time. It is also less amenable to examining partial activity compensation, as spending more time in any behaviour is necessarily expected to predict accumulating fewer counts across the rest of the day (approaching zero counts as time in the behaviour approaches 100\%). For complete activity compensation, however, we re-ran our analyses using the sum of all counts and obtained very similar findings (see Supplementary Tables 1 and 2).

We accept that we only tested the hypothesis of 'same-day' compensation. Our null findings in this respect replicate one previous study which found no evidence of same-day or next-day compensation (Baggett et al., 2010). Wilkin and Metcalf are correct that these data do not address the possibility that any activity compensation is delayed until later in the week. 
In summary, we agree that our study is neither a perfect nor a definitive test of the activitystat hypothesis. In the absence of definitive evidence, however, our rich behavioural data does give us an advantage over much other observational research. Our finding that there was no evidence of even partial, same-day activity compensation therefore contributes to the literature on this important public health question.

\section{Conflict of interest}

None

\section{$\underline{\text { References }}$}

Baggett, C. D., Stevens, J., Catellier, D. J., Evenson, K. R., Mcmurray, R. G., He, K. and Treuth, M. S. 2010. Compensation or displacement of physical activity in middle-school girls: the Trial of Activity for Adolescent Girls. Int J Obes (Lond), 34, 1193-9.

Fremeaux, A. E., Mallam, K. M., Metcalf, B. S., Hosking, J., Voss, L. D. and Wilkin, T. J. 2011. The impact of school-time activity on total physical activity: the activitystat hypothesis (EarlyBird 46). Int J Obes (Lond), 35, 1277-83.

Kriemler, S., Zahner, L., Schindler, C., Meyer, U., Hartmann, T., Hebestreit, H., Brunner-La Rocca, H. P., Van Mechelen, W. and Puder, J. J. 2010. Effect of school based physical activity programme (KISS) on fitness and adiposity in primary schoolchildren: cluster randomised controlled trial. BMJ, 340, c785.

Wilkin, T. and Metcalf, B. 2012. Testing the activitystat hypothesis. Prev. Med., 55, xxx-xxx. 
Additional supplement for Goodman et al., 2011. Testing the activitystat hypothesis: authors' response

Findings are consistent across three different methods of measuring physical activity

\section{1) Total activity compensation analyses}

Table 1: Association between time spent in different behaviours and physical activity across the whole day

\begin{tabular}{|c|c|c|c|c|c|c|c|}
\hline & & \multicolumn{6}{|c|}{$\begin{array}{l}\text { Regression coefficients ( } 95 \% \text { CI) for effect of percent duration of behaviour upon physical activity across the whole day (complete activity } \\
\text { compensation), measuring physical activity in terms of }\end{array}$} \\
\hline & & \multicolumn{2}{|c|}{$\begin{array}{l}\text { i) Percent time in MVPA [presented in } \\
\text { Table } 3 \text { in published paper] }\end{array}$} & \multicolumn{2}{|c|}{ ii) Mean RT3 activity counts per minute } & \multicolumn{2}{|c|}{ iii) Total daily sum of RT3 activity counts } \\
\hline & & Between-child $^{\text {a }}$ & Within-child $^{\text {b }}$ & Between-child $^{\text {a }}$ & Within-child $^{\text {b }}$ & Between-child $^{\text {a }}$ & Within-child $^{\text {b }}$ \\
\hline \multirow[t]{14}{*}{ Week } & Own home & $-.14(-.18,-.09) * * *$ & $-.15(-.21,-.09) * * *$ & $-3.6(-4.8,-2.4) * * *$ & $-3.8(-5.3,-2.3) * * *$ & $-1798(-2772,-824) * * *$ & $-2656(-3959,-1353) * * *$ \\
\hline & Friend's home & $.09(.01, .18)^{*}$ & $.01(-.10, .12)$ & $1.8(-0.5,4.2)$ & $0.6(-2.1,3.4)$ & $1982(65,3899)^{*}$ & $1390(-977,3757)$ \\
\hline & Other home & $-.06(-.16, .04)$ & $-.02(-.15, .11)$ & $0.0(-2.6,2.6)$ & $0.8(-2.6,4.2)$ & $1029(-1078,3135)$ & $1944(-941,4829)$ \\
\hline & School lessons & $-.12(-.21,-.04) * *$ & $-.14(-.26,-.02)^{*}$ & $-3.0(-5.2,-0.8)^{* *}$ & $-3.2(-6.1,-0.3)^{*}$ & $-6235(-7970,-4501) * * *$ & $-5874(-8324,-3424) * * *$ \\
\hline & PE/games & $.53(.36, .70)^{* * *}$ & $.41(.22, .61)^{* * *}$ & $13.1(8.8,17.4)^{* * *}$ & $10.6(5.7,15.6)^{* * *}$ & $8548(4873,12223) * * *$ & $7206(2887,11524)^{* *}$ \\
\hline & School breaks & $.25(.03, .47)^{*}$ & $.28(.00, .55)^{*}$ & $6.9(1.3,12.6)^{*}$ & $6.8(-0.3,14.0)$ & $-3687(-8330,955)$ & $-2711(-8897,3475)$ \\
\hline & Clubs \& tuition & $-.08(-.25, .09)$ & $.04(-.15, .24)$ & $0.0(-4.4,4.3)$ & $3.0(-1.9,7.9)$ & $924(-2689,4537)$ & $3588(-658,7835)$ \\
\hline & Non-home events & $.04(-.10, .19)$ & $-.04(-.21, .13)$ & $0.1(-3.7,3.8)$ & $-1.0(-5.1,3.2)$ & $717(-2393,3828)$ & $-175(-3790,3440)$ \\
\hline & Passive travel & $-.12(-.26, .02)$ & $-.11(-.30, .08)$ & $-2.3(-6.0,1.5)$ & $-2.1(-7.0,2.7)$ & $-2065(-5116,987)$ & $-1692(-5883,2500)$ \\
\hline & School active travel & $.56(.27, .86)^{* * *}$ & $.04(-.41, .50)$ & $11.6(3.7,19.6)^{* *}$ & $-1.5(-12.9,10.0)$ & $12305(6028,18583)^{* * *}$ & $-867(-10751,9017)$ \\
\hline & Non-school active travel & $.60(.39, .80)^{* * *}$ & $.52(.23, .82)^{* * *}$ & $15.9(10.6,21.1)^{* * *}$ & $12.0(4.6,19.4) * *$ & $11581(7285,15877)^{* * *}$ & $12130(5767,18493) * * *$ \\
\hline & Structured sport & $.29(.15, .43)^{* * *}$ & $.32(.15, .48)^{* * *}$ & $6.4(2.8,10.0)^{* *}$ & $6.1(1.9,10.3)^{* *}$ & $5743(2733,8753) * * *$ & $5061(1460,8661)^{* *}$ \\
\hline & Out-of-home play & $.26(.17, .36)^{* * *}$ & $.30(.19, .41)^{* * *}$ & $5.5(3.0,8.0)^{* * *}$ & $6.5(3.7,9.3)^{* * *}$ & $4969(2906,7031) * * *$ & $5680(3278,8083) * * *$ \\
\hline & Other & $-.09(-.38, .21)$ & $-.05(-.38, .29)$ & $-2.4(-10.1,5.2)$ & $-2.3(-10.6,6.1)$ & $-2459(-8818,3900)$ & $-2299(-9495,4897)$ \\
\hline \multirow{10}{*}{$\begin{array}{l}\text { Week } \\
\text {-end }\end{array}$} & Own home & $-.10(-.13,-.07) * * *$ & $-.06(-.10,-.02)^{* *}$ & $-2.9(-3.8,-2.0) * * *$ & $-2.1(-3.5,-0.7) * *$ & $-2170(-2833,-1506) * * *$ & $-1825(-2887,-763) * *$ \\
\hline & Friend's home & $.03(-.03, .10)$ & $.03(-.05, .11)$ & $-0.1(-2.1,1.9)$ & $-0.8(-3.5,2.0)$ & $-15(-1490,1459)$ & $-872(-2949,1205)$ \\
\hline & Other home & $-.05(-.09, .00)$ & $-.11(-.18,-.04) * *$ & $-0.6(-1.9,0.8)$ & $-1.8(-4.1,0.6)$ & $-355(-1381,670)$ & $-800(-2578,978)$ \\
\hline & Clubs \& tuition & $.00(-.30, .30)$ & $-.03(-.39, .33)$ & $0.0(-9.1,9.0)$ & $-1.2(-12.8,10.5)$ & $1651(-5069,8371)$ & $1206(-7609,10021)$ \\
\hline & Non-home events & $.01(-.05, .06)$ & $-.03(-.10, .03)$ & $0.9(-0.7,2.5)$ & $-0.2(-2.5,2.0)$ & $657(-529,1842)$ & $-518(-2243,1206)$ \\
\hline & Passive travel & $-.04(-.13, .06)$ & $-.10(-.22, .02)$ & $-0.2(-3.0,2.7)$ & $-2.0(-5.9,1.9)$ & $309(-1807,2424)$ & $-695(-3654,2264)$ \\
\hline & Non-school active travel & $.35(.19, .50)^{* * * *}$ & $.25(.05, .45)^{*}$ & $9.5(4.9,14.2)^{* * *}$ & $4.8(-1.7,11.3)$ & $7356(3924,10787) * * *$ & $4198(-744,9140)$ \\
\hline & Structured sport & $.28(.18, .37)^{* * *}$ & $.30(.18, .41)^{* * *}$ & $10.1(7.2,13.0) * * *$ & $11.2(7.5,14.9) * * *$ & $7434(5256,9612) * * *$ & $8164(5364,10963) * * *$ \\
\hline & Out-of-home play & $.26(.20, .32)^{* * *}$ & $.21(.14, .29)^{* * *}$ & $6.4(4.6,8.3)^{* * *}$ & $5.3(2.8,7.8)^{* * *}$ & $4513(3152,5875) * * *$ & $4329(2464,6195) * * *$ \\
\hline & Other & $.10(-.05, .26)$ & $.01(-.21, .24)$ & $2.0(-2.6,6.7)$ & $0.6(-6.7,7.9)$ & $1140(-2276,4555)$ & $943(-4638,6525)$ \\
\hline
\end{tabular}
$* \mathrm{p}<0.05, * * \mathrm{p}<0.01, * * * \mathrm{p}<0.001$. CI=confidence interval, Data from 345 children aged 8-13 in South-East England, collected 2002-2006. Between-child analyses across all days ( $\mathrm{N}=626$ weekdays, 451 weekend days), within-child analyses across pairs of days within the same child ( $\mathrm{N}=284$ weekday pairs, 185 weekend day pairs). ${ }^{\mathrm{a}}$ Adjusted for gender, age, weight status and income deprivation. ${ }^{\mathrm{b}}$ univariable analyses. $\uparrow$ not adjusted for clustering by school as model did not converge 


\section{2) Partial activity compensation analyses}

Note: Data for 'sum of all counts' not presented because there is no straightforward way to re-run this analysis using that data in a way that is readily interpretable. This is because even in the absence of activity compensation, one would expect a higher percentage of time spent in any one behaviour to predict the accumulation of a smaller sum of all counts across the rest of the day simply because less time is available during the rest of the day, with the sum approaching zero counts as the percent time in the behaviour approaches $100 \%$.

Table 2: Association between time spent in different behaviours and physical activity at other times

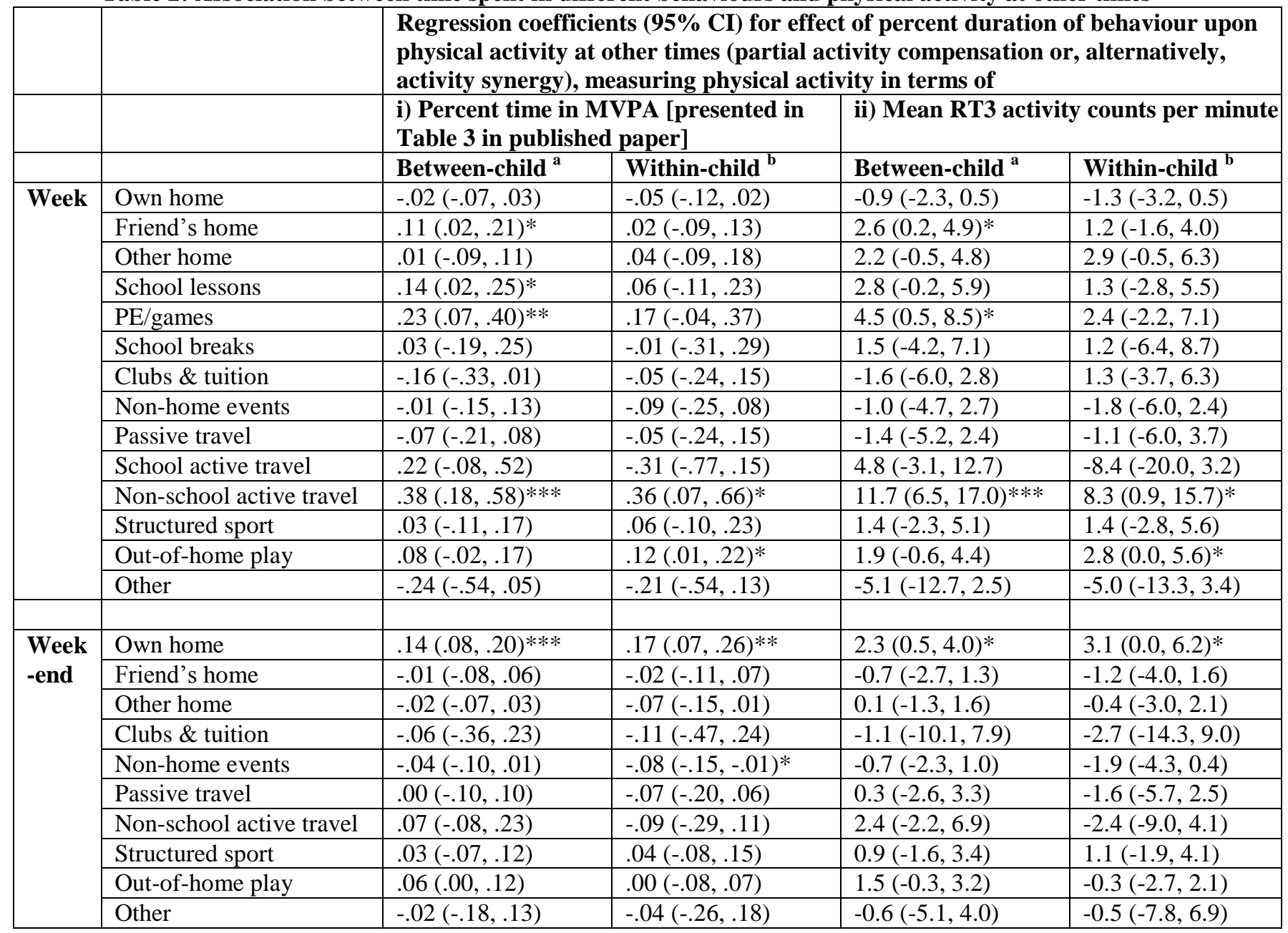

$* \mathrm{p}<0.05, * * \mathrm{p}<0.01, * * * \mathrm{p}<0.001 . \mathrm{CI}=$ confidence interval, Data from 345 children aged $8-13$ in South-East England, collected 2002-2006. Between-child analyses across all days ( $\mathrm{N}=626$ weekdays, 451 weekend days), within-child analyses across pairs of days within the same child ( $\mathrm{N}=284$ weekday pairs, 185 weekend day pairs). ${ }^{a}$ Adjusted for gender, age, weight status and income deprivation. ${ }^{b}$ univariable analyses. 